\title{
Use of Sulfur-Free Lignin as a novel soil additive: A multi-scale experimental investigation
}

Liu, Yaowu; Chang, Mushi; Wang, Qing; Wang, Yifan; Liu, Junyuan; Cao, Chengjun; Zheng, Wenle; Bao, Yiding; Rocchi, Irene

\section{Published in:}

Engineering Geology

Link to article, DOI:

10.1016/j.enggeo.2020.105551

Publication date:

2020

Document Version

Peer reviewed version

Link back to DTU Orbit

Citation (APA):

Liu, Y., Chang, M., Wang, Q., Wang, Y., Liu, J., Cao, C., Zheng, W., Bao, Y., \& Rocchi, I. (2020). Use of SulfurFree Lignin as a novel soil additive: A multi-scale experimental investigation. Engineering Geology, 269, 105551. https://doi.org/10.1016/j.enggeo.2020.105551

\section{General rights}

Copyright and moral rights for the publications made accessible in the public portal are retained by the authors and/or other copyright owners and it is a condition of accessing publications that users recognise and abide by the legal requirements associated with these rights.

- Users may download and print one copy of any publication from the public portal for the purpose of private study or research.

- You may not further distribute the material or use it for any profit-making activity or commercial gain

- You may freely distribute the URL identifying the publication in the public portal 
1 A multi-scale experimental investigation of Sulfur-Free Lignin

as novel soil stabilizer

3 Yaowu Liu ${ }^{a}$, Mushi Chang ${ }^{a}$, Qing Wang ${ }^{a^{*}}$, Yifan Wang ${ }^{a}$, Junyuan Liu ${ }^{a}$,

4 Chengjun Cao $^{a}$, Wenle Zheng ${ }^{a}$, Irene Rocchi ${ }^{b}$

5 a. College of Construction Engineering, Jilin University, Changchun 130026, China

6 b. Department of Civil Engineering, Technical University of Denmark, Brovej,

7 Building 119, $2800 \mathrm{Kgs}$, Lyngby, Denmark

8 Abstract

9 With the rapid process of urbanization, more and more infrastructures

10 are inevitably built on problematic soils, which require improvement and

11 reinforcement. In this study, a novel material Sulfur-Free Lignin (SFL),

12 which is a by-product of bioethanol industry, was used to improve the soil's

13 geotechnical behavior as a sustainable, nontoxic and eco-friendly stabilizer.

14 To systematically investigate the geotechnical properties of SFL-stabilized

15 soil, the natural soil was modified by adding five different contents $(3,7$,

1610,12 and 15\%) and then a series of geotechnical experiments including

17 unconfined compressive strength (UCS), Atterberg limits tests, electrical

18 resistivity and $\mathrm{pH}$ were carried out after $1,7,28,60$-days curing. In

19 addition, to preliminary investigate the stabilization mechanism, the

20 mineral composition, function group and microstructure characteristic

21 were also studied through X-Ray Diffraction (XRD), Fourier Transform 
22 Infrared Spectroscopy (FTIR), Mercury Intrusion Porosity (MIP) and

23 Scanning Electron Microscopy (SEM) tests. The test results demonstrate

24 that with increasing SFL content, the electrical resistivity gradually

25 decrease, on the contrary, the Atterberg limits show a slightly increase.

26 However, the $\mathrm{pH}$ values are unchanged indicating the SFL would not lead

27 to $\mathrm{pH}$ contamination risk which is usually caused by traditional chemical

28 stabilizer. Furthermore, the 10\% SFL-stabilized soil after 60 days of curing

29 shows the greatest strength, which increases about $600 \%$ compared to the 30 natural soil. Furthermore, the relationship between $\mathrm{E}_{50}$ and UCS is

31 generally proportional. According to the results of MIP and SEM, the

32 strength improvement could contribute to a smaller total volume of pores,

33 reduction in the mean size of the pores and stronger bonds former by SFL

34 between isolated grains. In addition, the results of XRD and FTIR test

35 reveal there is no new mineral and function group generated after adding

36 SFL. Above all, the natural soil stabilized by SFL shows a satisfactory

37 engineering performance and it would be a win-win solution to utilize SFL

38 as a soil stabilizer for soil improvement in civil engineering and waste

39 elimination in bioethanol industry.

40 Key words: Sulfur-Free Lignin, soil stabilization, curing time, eco-friendly

41 and sustainable stabilizer, multi-scale investigation 


\section{Introduction}

With the expanding process of urbanization, more and more civil

45 engineering structures, such as rail/road subgrade, foundations and

46 embankments, are inevitably constructed above problematic soils, which

47 could cause safety and reliability problems for the structure if the soil

48 properties are not improved or stabilized. Stabilization of problematic soils

49 has traditionally been achieved by mixing grout or other chemical agents

50 to increase soil shear strength, decrease its compressibility and alter other

51 undesirable engineering properties, such as high permeability (Karim et al.,

52 2013; Jafer et al., 2018; Wang et al., 2019a). At present, the traditional

53 chemical cementitious agents involving Ordinary Portland Cement (OPC)

54 and lime have been used as preferred binder materials to enhance the

55 engineering properties of weak soils and achieve good results (Chen and

56 Wang, 2006; Modarres and Nosoudy, 2015; Liu et al., 2019b). However,

57 these cementitious agents are associated with some considerable problems:

58 (i) to produce them, huge amounts of energy are consumed and large $\mathrm{CO}_{2}$

59 emission occur in the clinker production process. For example, the typical

60 manufacturing of $1 \mathrm{t}$ OPC consumes $5000 \mathrm{MJ}$ and releases about $0.95 \mathrm{t}$

$61 \mathrm{CO}_{2}$ and overall this accounts for $4-5 \%$ of global $\mathrm{CO}_{2}$ emissions (Thives

62 and Ghisi, 2017; Zhang et al., 2017b). (ii) the soils stabilized with these

63 materials show a remarkable increasing trend in $\mathrm{pH}$ values, which may

64 pose a risk of environmental contamination (Sreekrishnavilasam et al., 
65 2007; Jiangying et al., 2008). (iii) the performance of treated soil is barely

66 satisfactory under dynamic cyclic loads, due to excessively brittle

67 properties. The above problems push to find innovative soil stabilizers to

68 improve the geotechnical properties of weak soils, while meeting the

69 requirements of being eco-friendly, low-carbon and energy-efficient.

70 Therefore, various alternative agents (such as lignin, fly ash, reactive $\mathrm{MgO}$,

71 rice husk ash and wastepaper sludge ash) based on industrial by-products

72 or waste materials have been tested in the attempt to replace OPC in the

73 process of soil stabilization (Tingle et al., 2007; Rahmat and Ismail, 2011;

74 Lee and Shang, 2014; Liu et al., 2019a; Wang et al., 2019b).

75 In recent years, lignin begins to draw more and more attention from

76 researchers as a potential soil stabilizer due to its use as a renewable

77 biomass. In the past industrial processes, massive lignin amounts were

78 obtained in the form of lignosulfonate (LS) from paper pulping industry

79 (Chio et al., 2019). Due to the increasingly grim energy safety problems

80 caused by massive consumption of non-renewable fossil fuels, bio-based

81 energy production has flourished under the support of advancing

82 technology. The second-generation ethanol production especially

83 overcomes the concerns regarding food security by utilizing readily

84 available lignocellulosic biomasses (such as corncob, maize straw and tree

85 leaves) instead of crops to produce bioethanol and shows a huge potential

86 to replace petroleum-based resources (Yano et al., 2009; Pourhashem et al., 
2016; Wang and Cheng, 2018). However, a large amount of lignin is left as

88 a by-product or waste material in the process of generating bioethanol. This

89 kind of lignin based on bioethanol production is different from

90 lignosulfonate from pulping industry, as it is sulfur free and contains more

91 lignin (about $50-75 \%$ ) with moderate macromolecular size making it more

92 similar to native lignin.

93 Currently, considerable research has been conducted to investigate the

94 performance of lignosulfonate (LS) from pulping industry as an innovative

95 reinforcement geomaterials. Tingle and Santoni treated clay soils and silty

96 sands with different LS quantities and tested the load-bearing capacity of

97 the stabilized soils (Santoni et al., 2002; Tingle and Santoni, 2003). The

98 results showed all stabilized soils had a significant strength improvement.

99 They also preliminarily discussed the possible stabilization mechanism of

100 LS (Tingle et al., 2007). Surdahl et al. investigated the performance of

101 lignosulfonate-stabilized soils for dust control, rutting, raveling and

102 washboarding over a 24-month period through a field test in south central

103 Arizona, America (Surdahl et al., 2007). The physical monitoring results

104 showed the LS stabilized have a satisfactory improvement overall.

105 Indraratna, Vinod et. al $(2008 ; 2010)$ and Alazigha et al. (2018) used LS

106 to stabilize dispersive and expansive soil respectively and evaluated the

107 behavior of erosion resistance and swelling resistance. Vakaili et. al (2018)

108 also studied the internal erosional behavior of dispersive clay stabilized 
109 with LS and similarly to Indraratna et al. the LS-stabilized soil showed a

110 significant reduction in soil dispersivity. In addition, Zhang et al. (2015;

$1112017 \mathrm{a}, 2018 \mathrm{a})$ comprehensively assessed the engineering performance of

112 LS-stabilized silty soil as pavement subgrade through a series of laboratory

113 and field tests, employing shear-wave velocity and thermal resistivity as

114 fast and nondestructive methods to evaluate the strength performance for

115 LS-stabilized soils. However, scarce research has been conducted to study

116 the engineering performance of bioethanol-derived sulfur-free lignin as a

117 geotechnical stabilizer, even if sulfur-free lignin has advantages over LS

118 and its production is increasing rapidly along with the flourishing

119 bioethanol industry.

120 In view of the above, the purpose of this study is to investigate the

121 feasibility of using Sulfur-Free Lignin (SFL) based on a bioethanol

122 industry by-product to stabilize soil, improving its geotechnical properties

123 of soil, while reducing product energy consumption and $\mathrm{CO}_{2}$ emissions by

124 using a waste. A series of laboratory experiments were conducted including

125 Atterberg limits, Unconfined Compressive Strength (UCS), $\mathrm{pH}$, electrical

126 conductivity, X-Ray Diffraction (XRD), Fourier Transform Infrared

127 Spectroscopy (FTIR), Mercury Intrusion Porosimetry (MIP) and Scanning

128 Electron Microscopy (SEM). Based on the analysis of the experiments, the

129 effects of different SFL contents and different curing times were obtained.

130 In addition, the stabilization mechanism of Sulfur-Free Lignin is also 
131 preliminary analyzed in this paper.

\section{Materials and methods}

1332.1 Soil samples

134 The soil samples used in this study were extracted from about $40 \mathrm{~cm}$ 135 depth below ground level in Qian'an city that is located in the western of 136 Jilin Province, China [N45 02'25.490”, E123 47’1.148']. The particle

137 size distribution (measured by Laser Diffraction Particle Analyser) of the

138 soil used in this study is shown in Fig.1. The main geotechnical properties

139 of the soil are summaries in Table. 1 along with the results of total dissolved

140 solids, $\mathrm{pH}$ and organic matter content. The chemical elemental components

141 of the soil were determined by X-ray Fluorescence and the result are listed

142 in Table. 2. As shown in Fig.2, the X-ray Diffraction quantitative analysis

143 indicates that the main mineral components include Quartz, clay minerals

144 and Plagioclase, accounting for $38.7,22.9$ and $16.4 \%$ respectively.

145 Moreover, the main clay minerals are the by Illite/Smectite mixer layer and

146 Illite, which are the most common crystalline minerals (Budhu, 2008). 


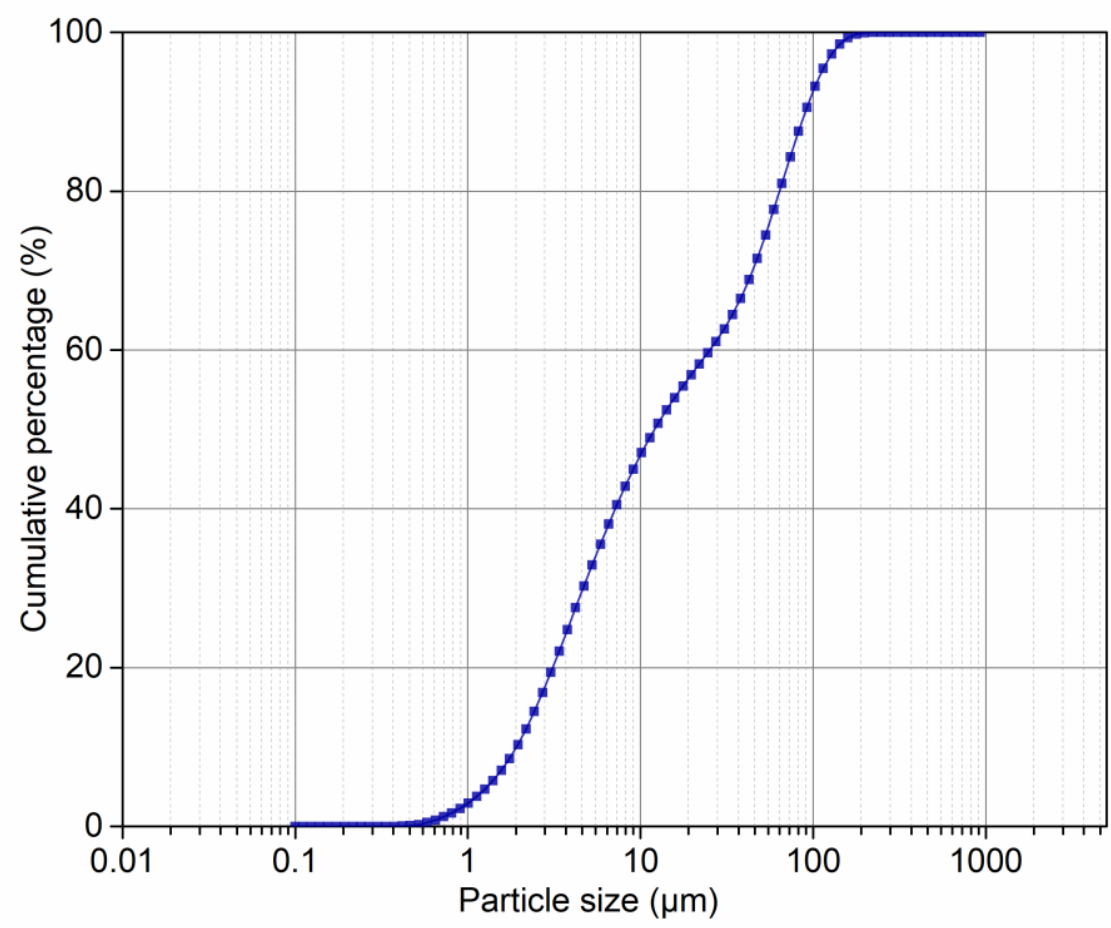

Fig. 1. Grain size distribution of the natural soil.

Table 1

Geotechnical properties of the tested soil

\begin{tabular}{lr}
\hline Property & Values \\
\hline Soil natural density $\left(\mathrm{g} / \mathrm{cm}^{3}\right)$ & 1.909 \\
Natural water content w $(\%)$ & 21.58 \\
Sand \% $(2-.075 \mathrm{~mm})$ & 18.5 \\
Silt \% $(0.075-0.005 \mathrm{~mm})$ & 53.4 \\
Clay \% (<0.005 mm) & 29.1 \\
liquid limit (\%) & 34.85 \\
plasticity limit $(\%)$ & 18.47 \\
plasticity index PI & 16.49 \\
Optimum moisture content $(\%)$ & 15.6 \\
Maximum dry unit weight $(\mathrm{Ydmax})\left(\mathrm{kN} / \mathrm{m}^{3}\right)$ & 1.781 \\
Total dissolved solids $(\mathrm{mmol} / \mathrm{kg})$ & 43.92 \\
Organic matter $(\%)$ & 0.40 \\
$\mathrm{pH}$ & 8.7 \\
\hline
\end{tabular}


Table 2

The chemical composition of the tested soil based on the XRF

\begin{tabular}{lr}
\hline Composition & percentage $(\%)$ \\
\hline Silicon oxide $\left(\mathrm{SiO}_{2}\right)$ & 66.27 \\
Aluminum oxide $\left(\mathrm{Al}_{2} \mathrm{O}_{3}\right)$ & 11.55 \\
Iron oxide $\left(\mathrm{Fe}_{2} \mathrm{O}_{3}\right)$ & 2.51 \\
Ferric oxide $(\mathrm{FeO})$ & 0.40 \\
Calcium oxide $(\mathrm{CaO})$ & 5.04 \\
Magnesium oxide $(\mathrm{MgO})$ & 1.69 \\
Potassium oxide $\left(\mathrm{K}_{2} \mathrm{O}\right)$ & 2.88 \\
Sodium oxide $\left(\mathrm{Na}_{2} \mathrm{O}\right)$ & 2.57 \\
Titanium oxide $\left(\mathrm{TiO}_{2}\right)$ & 0.50 \\
Phosphorus oxide $\left(\mathrm{P}_{2} \mathrm{O}_{5}\right)$ & 0.07 \\
Manganese oxide $(\mathrm{MnO})$ & 0.07 \\
Loss on ignition $(\mathrm{LOI})^{\mathrm{a}}$ & 6.33 \\
Other & 0.10 \\
\hline
\end{tabular}

Note: LOI means value of loss on $950^{\circ} \mathrm{C}$ ignition.

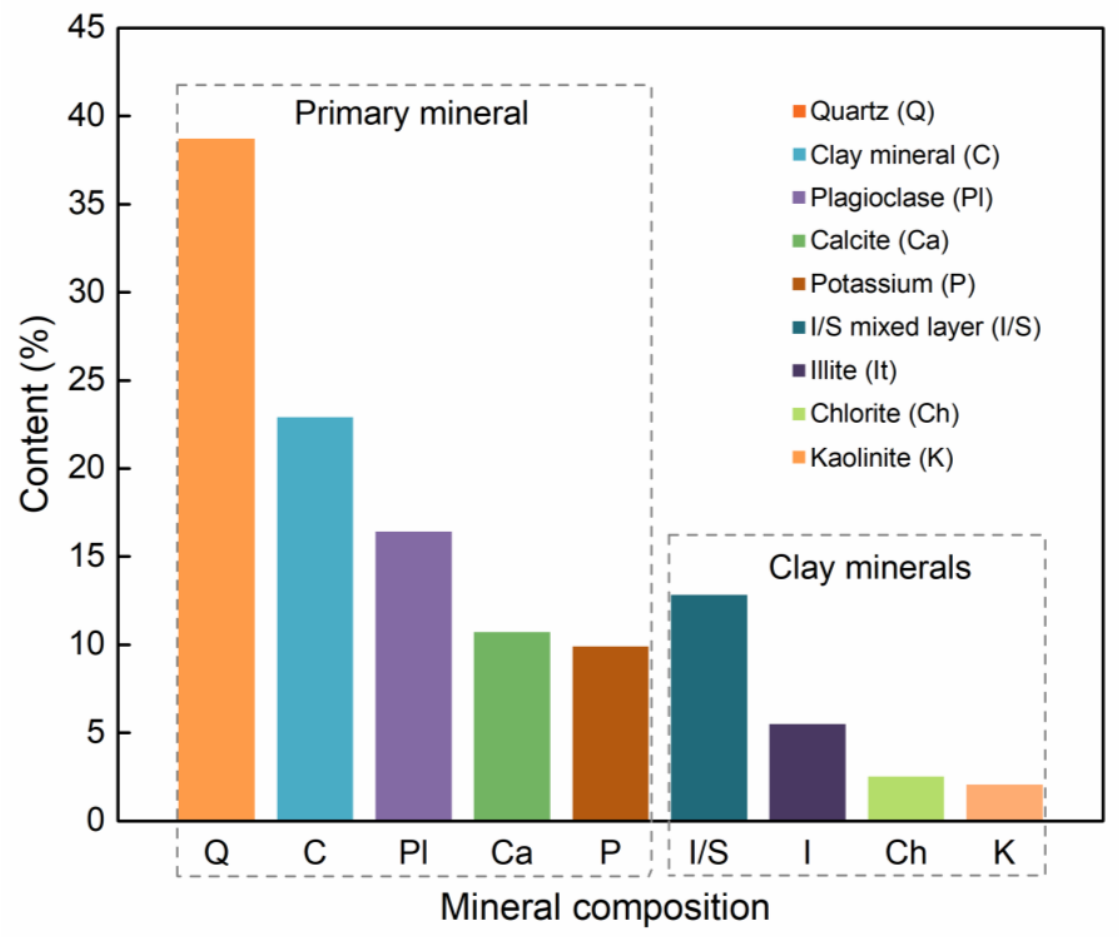

Fig. 2. Mineral composition of the natural soil. 
154 The Sulfur-Free Lignin (SFL) used in this study was supplied by a corn-

155 based bioethanol corporation in Shandong Province, China. The main

156 components according to the supplier are $91.2 \%$ lignin, $0.12 \%$ residual

157 cellulose/hemicellulose, and $0.67 \%$ ash content. The low ash content

158 indicates the high purity levels of SFL as obtained in the processing of bio-

159 ethanol. The SFL used in this study is a light-brown powder with wood

160 fragrance odour that is slightly soluble having neutral $\mathrm{pH}$.

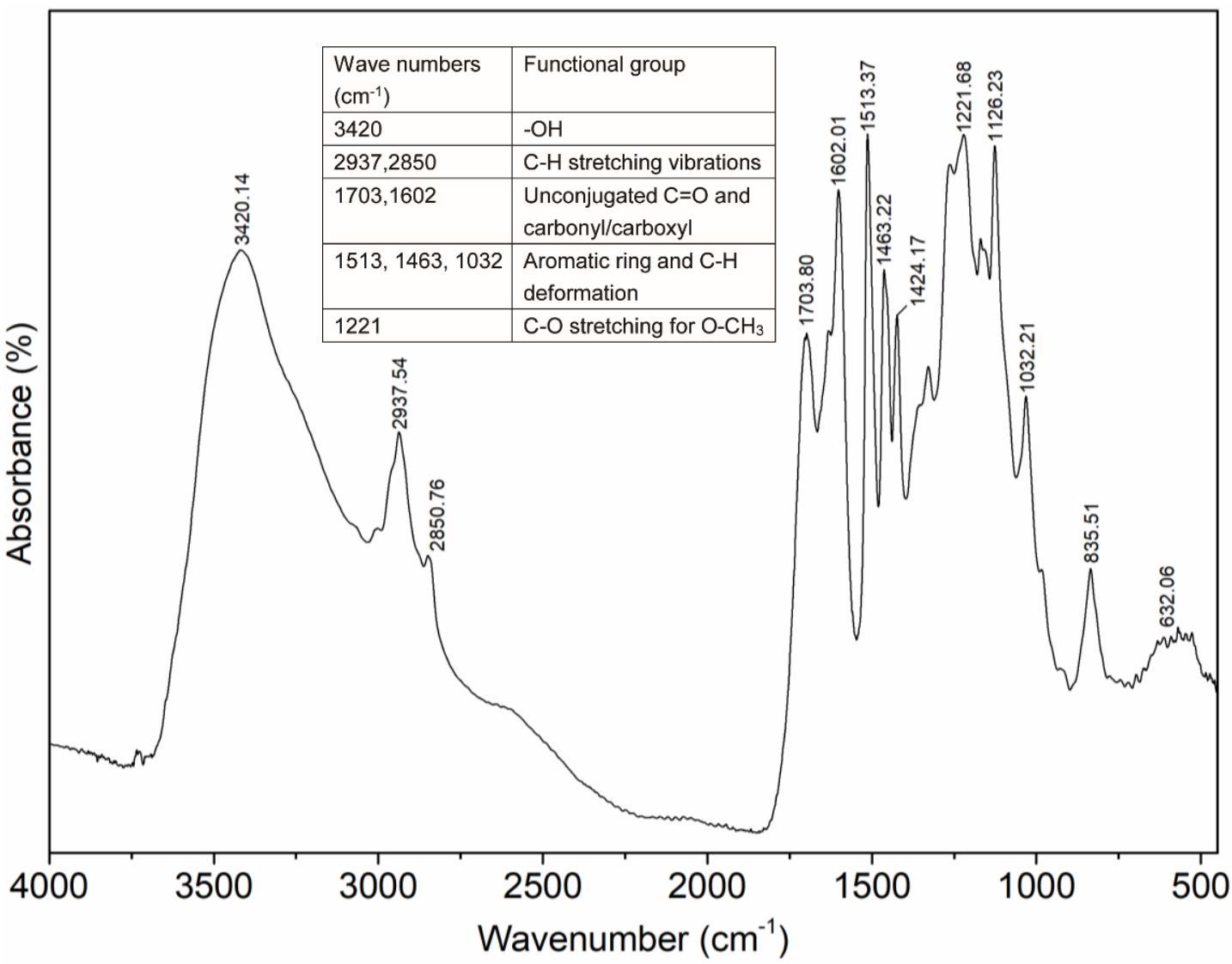

Fig. 3. FTIR spectra of the sulfur-free lignin.

162 The functional groups of SFL were determined through Fourier

163 Transform Infrared Spectroscopy (FTIR). The wavenumbers and the 164 important band identification for SFL are present in Fig. 4. It is evident 
165 from Fig. 4 that the SFL contains different function groups such as C-O

166 stretching for methoxyl groups $\left(1221 \mathrm{~cm}^{-1}\right)$, deformation of aromatic ring

167 and $\mathrm{C}-\mathrm{H} \quad\left(1032,1463\right.$ and $\left.1513 \mathrm{~cm}^{-1}\right)$, unconjugated $\mathrm{C}=\mathrm{O}$ and

168 carbonyl/carboxyl $\left(1703,1602 \mathrm{~cm}^{-1}\right), \mathrm{CH}$ stretching vibrations $(2937,2850$

$\left.169 \mathrm{~cm}^{-1}\right)$ and $\mathrm{OH}\left(3420 \mathrm{~cm}^{-1}\right)$.

$170 \quad 2.3$ Sample preparation

171 The natural soil collected from the site was left to air-dry for several

172 days (not less than 3 days) rather than oven dried to avoid altering the

173 mineral composition. Then the soil lumps were pulverized with a rubber

174 hammer and passed through a $2 \mathrm{~mm}$ sieve. Six different SFL amounts - 0,

$1753,7,10,12$ and 15\%- were added as a percentage of the soil dry weight.

176 Before adding distilled water, the mixture of SFL and natural soil was

177 mixed for approximately 5 minutes to ensure homogenisation. The same

178 operation was also carried out after mixing a predetermined amount of

179 distilled water. Afterwards, the mixture was tightly sealed in a metal bucket

180 for $24 \mathrm{~h}$ until the moisture was distributed homogeneously. It should be

181 noted that the amount of water employed for the moisture content in all

182 specimens was the optimum moisture content of the natural soil.

183 Subsequently, the mixture was placed into a steel cylindrical mould with

184 specific dimensions $(39.1 \mathrm{~mm}$ inner diameter and $80 \mathrm{~mm}$ height $)$ and 185 statically compacted to a density equal to $95 \%$ the maximum density of the 
186 natural soil. Finally, the demoulded specimens were wrapped with cling

187 film, labelled and sealed with waterproof bags, then stored in a curing room

188 with $20^{\circ} \pm 2{ }^{\circ} \mathrm{C}$ and relative humidity $92 \pm 3 \%$ for either $1,7,28$ and 60

189 days.

$190 \quad 2.4$ Testing methods

191 In this study, the two-electrode probe method was adopted to determine

192 the electrical resistivity of the SFL-stabilized soil using the Anbai AT810A

193 Precision LCR Meter instrument (Fig.4). Two-electrode probes were used

194 to make full contact with the specimens and measure the voltage and

195 current. According to Ohm's law, the electrical resistivity of SFL-stabilized

196 soil, $\rho(\Omega \mathrm{m})$, was calculated based on the following equation:

$$
\rho=\frac{\Delta U}{I} \frac{A}{L}
$$

198 Where $\Delta U$ is the applied voltage (V), $I$ is the applied electrical current

199 (A), $A$ is the cross-sectional area of the samples $\left(\mathrm{m}^{2}\right)$ and $L$ is the height 200 of the samples (m). In this experiment, the voltage and electric frequency 201 of the instrument were set to $2 \mathrm{~V}$ and $10 \mathrm{~Hz}$, respectively, and in order to 202 avoid temperature effects, the electrical resistivity tests were performed in 203 a constant room temperature $\left(25^{\circ} \mathrm{C}\right)$. The $\mathrm{pH}$ tests were performed using a 204 PB-10 probe (Sartorius Crop. Germany) according to ASTM D4972 205 (ASTM, 2007). The Atterberg limits for the natural and stabilized samples 206 were measured by fall cone test as per ASTM D4318 (ASTM, 2010). To 
207 characterize the strength of the SFL-stabilized soil, Unconfined 208 Compressive Strength tests (UCS) were carried out in accordance to ASTM 209 D4219 (ASTM, 2002). A fixed loading rate equal to $2 \mathrm{~mm} / \mathrm{min}$ was used 210 and the peak normal stress in the stress-strain curve was selected as the 211 compressive strength.

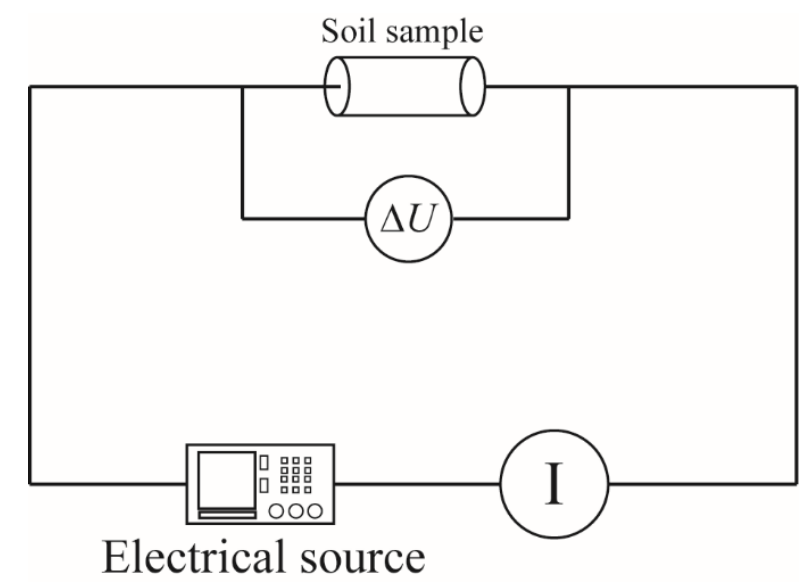

Fig. 4. Schematic diagram of the two-electrode probe method.

213 To investigate the function groups, elemental and mineral composition 214 of SFL-stabilized soil, the Fourier Transform Infrared (FT-IR) Spectra, X215 ray diffraction and X-ray fluorescence tests were conducted. The FT-IR 216 spectrum was measured and recorded in the mid-IR region of $475-4000$ $217 \mathrm{~cm}^{-1}$ by a Thermo Scientific Nicolet iS10 Fourier transform infrared 218 spectromerter (America). An X-ray diffractometer (D/MAX-2500, Rigaku, 219 Japan) with a $\mathrm{Cu}-\mathrm{K} \alpha$ radiation source at a voltage of $30 \mathrm{kV}$ was used to 220 conduct mineral pattern testing. The setting scanning angle ranged from $2212.6^{\circ}$ to $45^{\circ}$ with a scanning speed of $6^{\circ}(2 \theta) / \mathrm{min}$. In order to perform 222 quantitative analysis of the mineralogical composition, the "K-value" 223 method described in SY/T 5163-2010 (China, 2010a) was adopted. The 
224 elemental composition for all samples were measured and analyzed by a

225 tube-above wavelength dispersive X-ray fluorescence spectrometer (ZSX

226 primus II, Rigaku, Japan) and EZ-scan software according to GB/T 14506

227 Standard (China, 2010b).

228 The pore size characteristics were investigated by Mercury Intrusion

229 Porosimetry tests (MIP), using an AUTO-PORE 9500 device

230 (Micromeritics Instrument Corp. America), which can reach a maximum

231 pressure of $228 \mathrm{MPa}$. As suggested by Delage (1984), the tested specimens

232 were subsampled into $1 \mathrm{~cm}^{3}$ cubes and were then completed dehydrated by

233 freeze-drying, which involves rapid freezing in liquid nitrogen (boiling

234 point $-196^{\circ} \mathrm{C}$ ) followed by sublimation in a true vacuum. Scanning Electron

235 Microscopic analysis (SEM) has also been used to identify the

236 microstructure of natural and SFL stabilized soils after being exposed for

237 to different curing periods. A Phenom ProX Desktop scanning electron

238 microscope (Thermo Fisher Scientific, America) was used with an

239 accelerating voltage of $10 \mathrm{kV}$. The pretreatment process for SEM tests was

240 almost the same as for MIP tests, however, the specimens were sputter-

241 coated with a thin layer of gold prior to the SEM testing to improve the

242 image quality and avoid electrical charging. 


\section{Results and discussion}

2443.1 Electrical resistivity and $\mathrm{pH}$

245 Fig. 5(a) shows the electrical resistivity of the stabilized soil as a 246 function of Sulfur-Free Lignin content. It can be found that the natural soil

247 has the maximum electrical resistivity, on average equal to $102.43(\Omega \bullet \mathrm{m})$,

248 and the electrical resistivity decreases with increasing SFL content. In 249 previous studies, some researchers (McCarter, 1984; Samouëlian et al., 250 2005; Cai et al., 2013) reported that two main factors control the electrical 251 resistivity: (1) the degree of water saturation (water content) and (2) the 252 electrical resistivity of pore fluid (solute concentration). The water content 253 is not relevant in this case since this is the same for all samples (17.5\%). 254 Thus, the results may be due to the SFL powder mixing with some of the 255 soluble salts used in the production process. In the process of corn-based 256 bioethanol production, the lignocellulose structure of corncobs and corn 257 stover are pretreated by high-pressure steam to break bonds between 258 polymeric components. The SFL is then separated from the steam solution 259 through delignification reactions (adding alkaline compounds to sediment 260 the lignin and acids to neutralize the $\mathrm{pH}$ ) (Rocha et al., 2012). As a result, 261 the solute ion concentration in the pore fluid increases with SFL, resulting 262 in a decrease in the electrical resistivity. 

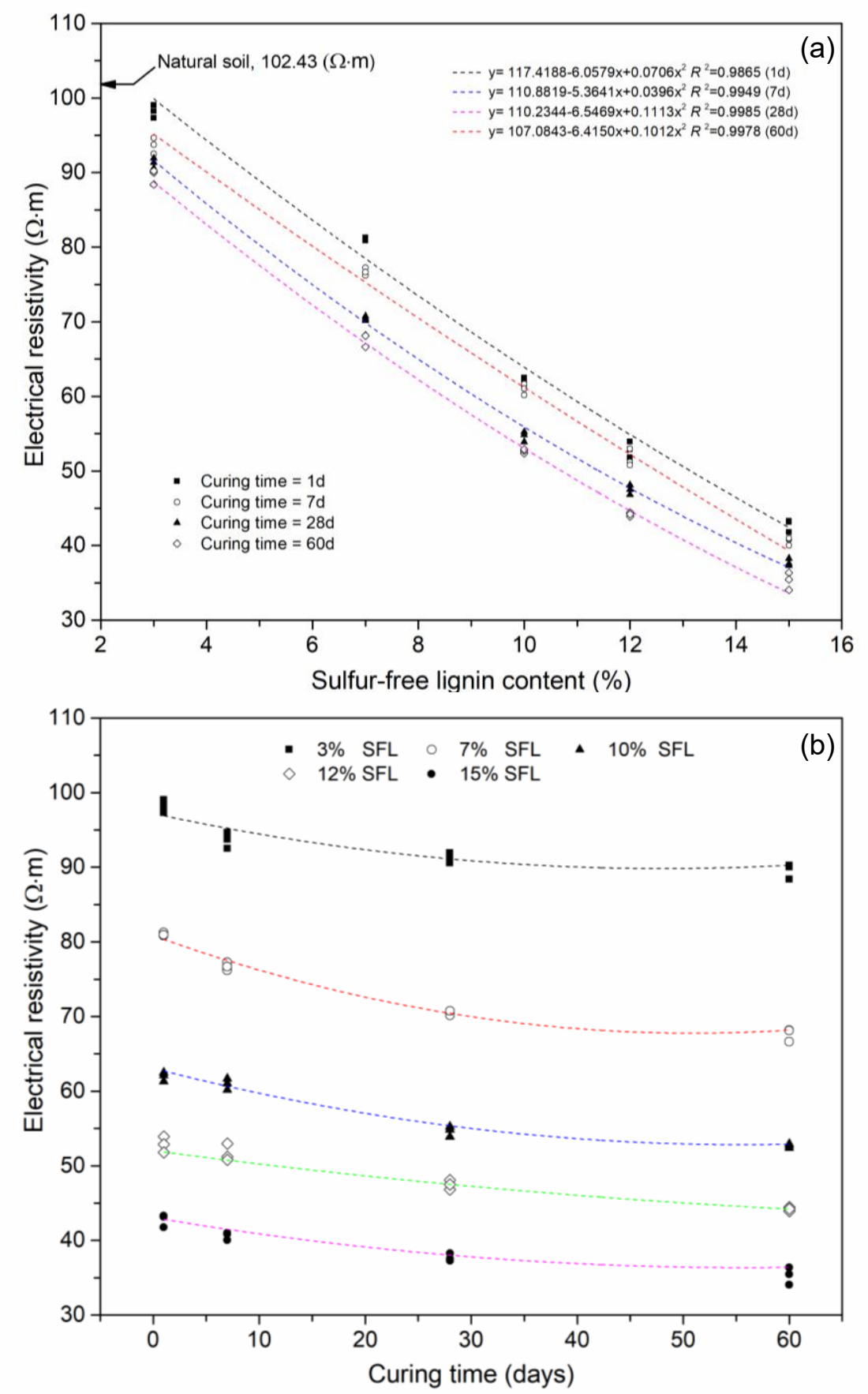

Fig. 5. Electrical resistivity for samples in terms of (a) sulfur-free lignin and (b) curing time.

265 Fig 5(b) shows the relationship between the electrical resistivity of

266 SFL-stabilized soil and curing time. The electrical resistivity of the 267 stabilized soil shows a slight decreasing trend with increasing number of 268 curing days. This may be because the ions in the pore fluid diffuse more 
269 with time. This result is not consistent with the research by Void et al. (2012)

270 who did not observe any clear change in the electrical conductivity with

271 curing time, which may be due to a different measuring method.

272 Fig. 6 presents the variation of $\mathrm{pH}$ for the stabilized soil with different

273 SFL contents. The $\mathrm{pH}$ values decrease from 8.7 to 8.2 , showing a very

274 slight reducing trend with SFL content up to $15 \%$. This means that utilizing

275 SFL to stabilize soil would not lead to $\mathrm{pH}$ contamination risk as usually

276 caused by traditional chemical stabilizer (Chew et al., 2004; Sharma et al.,

277 2012) although the ion concentration in the pore fluid increases according

278 to the electrical resistivity result.

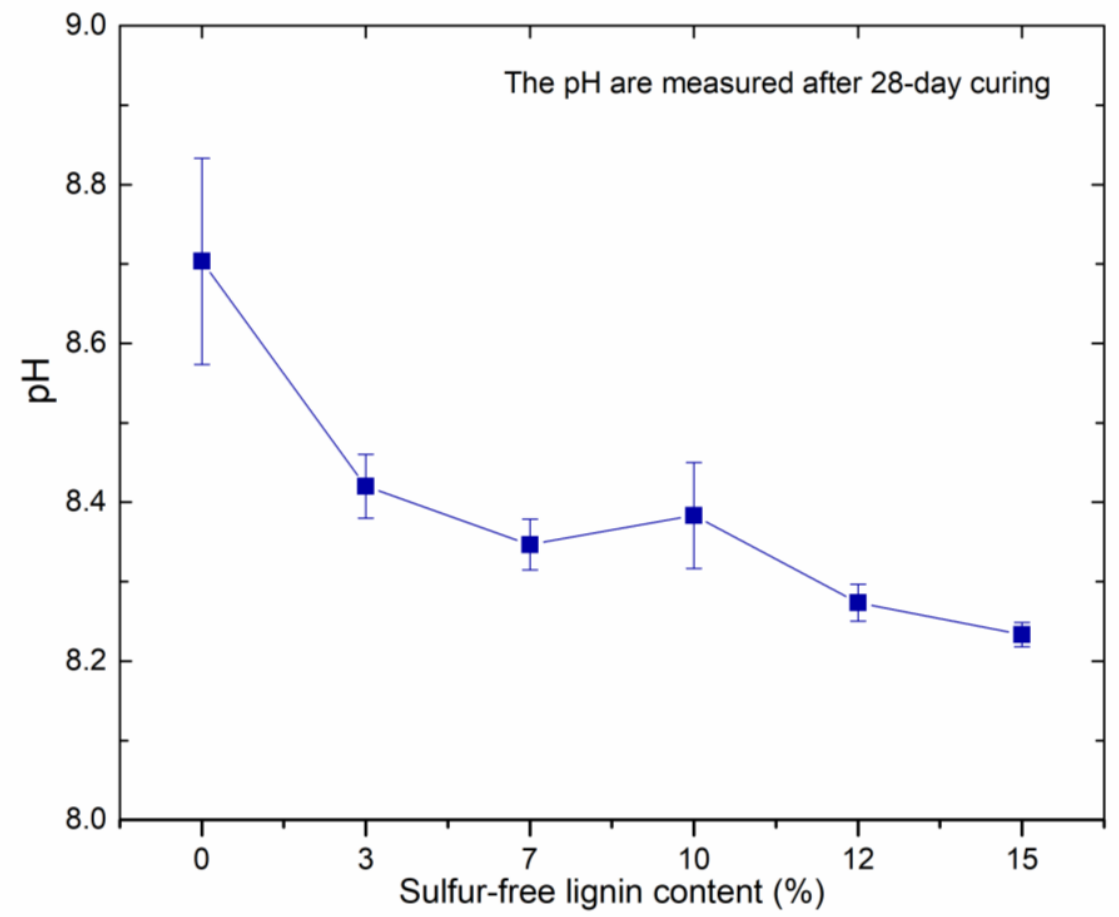

Fig. 6. Variation of $\mathrm{pH}$ values for different sulfur-free lignin content. 
The Atterberg limits are a basic measurement of key water contents for

282 a fine-grained soil, which include shrinkage limit, plastic limit and liquid

283 limit. The plastic limit $\left(w_{P}\right)$ defines the water content at which a soil

284 transitions from a semi-solid to a plastic state, while the liquid limit $\left(w_{L}\right)$

285 defines the water content at which the soil behavior changes from plastic

286 to liquid. The variation in liquid limit $\left(w_{L}\right)$, plastic limit $\left(w_{P}\right)$ and plastic

287 index $\left(I_{P}=w_{L}-w_{P}\right)$ of the stabilized soil variation with increasing SFL

288 content after 28-days curing is plotted in Fig. 7. It can be seen from Fig.

289 7(a) that both $w_{L}$ and $w_{P}$ increase with SFL content, but $w_{L}$ shows a more

290 significant growth reaching about $18 \%$ more compared to the natural soil,

291 which leads to $I_{P}$ increasing by $24 \%$ when adding $15 \%$ SFL, resulting in

292 the stabilized soils change from medium plastic $\left(7<I_{P}<17\right)$ to highly

293 plastic $\left(I_{P}>17\right)$. A similar result was reported by Zhang et al. (2018b) who

294 used lignosulfonate from pulping industry to improve silt soils. The

295 increase in Atterberg limits may be primarily because the fine soil particles

296 are coated and bonded to coarse particles by the lignin fibers and the soil

297 structure becomes more stable, resulting in more water being required to

298 achieve the state transitions. Another reason may be the low solubility of

299 SFL, which leads to strong water holding capacity in the stabilized soil.

300 With respect to influence of the curing time on $I_{P}$, as shown in Fig. 7(b),

301 there is no clear trend as the SFL content increases. 

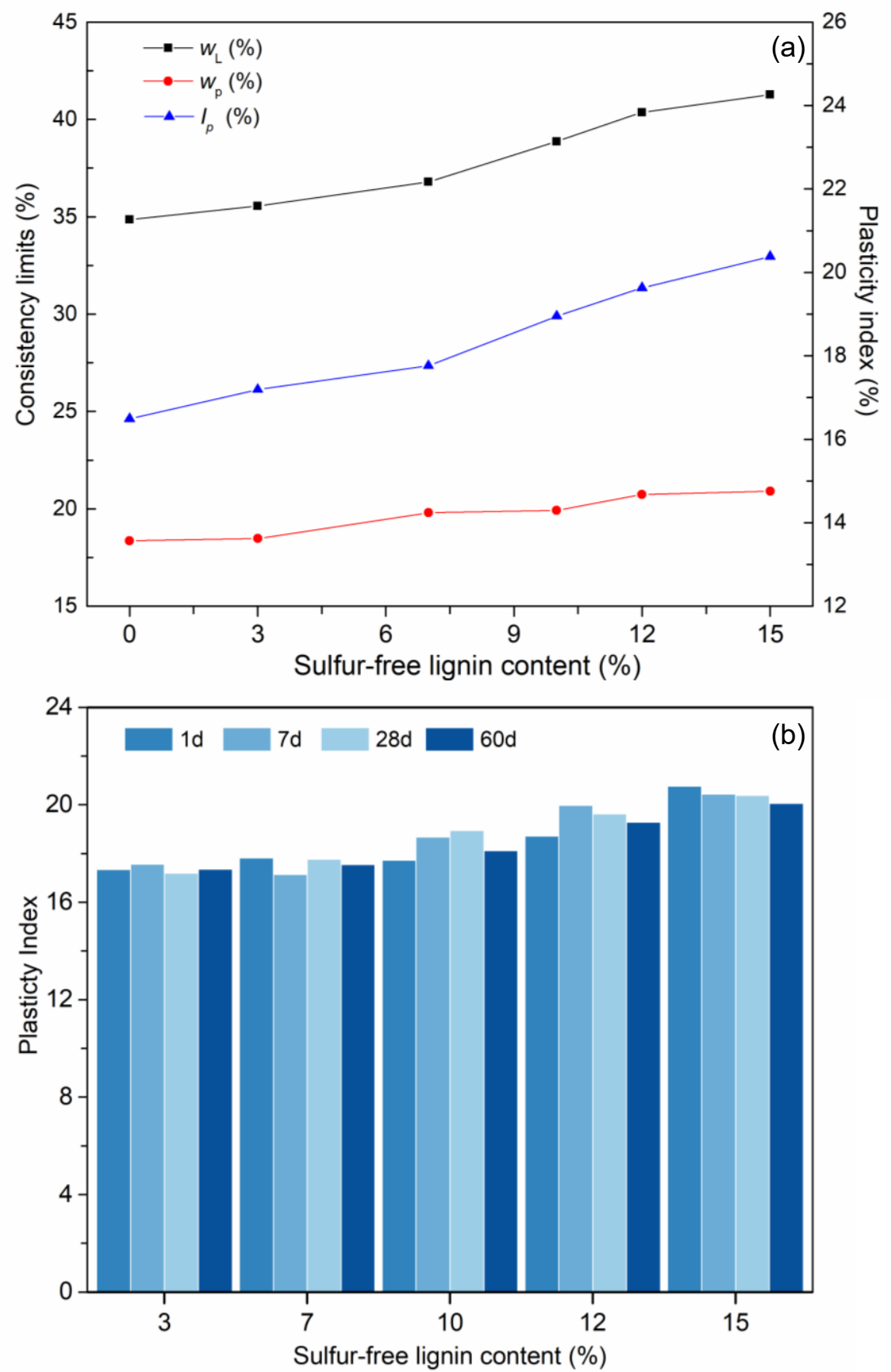

Fig. 7 (a) Variations of Atterberg limits for different sulfur-free lignin contents after 28days curing and (b) Variations of plasticity index for different sulfur-free lignin after different curing days.

303 3.3 Stress-strain behavior and strength characteristics

304 Fig.8 shows the stress-strain behavior of natural and the SFL stabilized 305 soils after 60-day curing time, as obtained from Unconfined Compressive 
306 Strength tests (UCS). The stress-strain behavior of all samples shows 307 strain-hardening where the stress gradually increases with strain until an 308 approximately constant value is reached at failure. This stress-strain 309 behavior is entirely different from that of Ordinary Portland Cement (OPC) 310 or lime stabilized soil (Nalbantoglu, 2006; Farouk and Shahien, 2013; Önal, 311 2015) and the SFL stabilized soil shows more ductile properties. Based on

312 the stress-strain curve, the UCS strength $\left(\sigma_{c}\right)$ and deformation modulus $\left(\mathrm{E}_{50}\right)$ 313 can be determined.

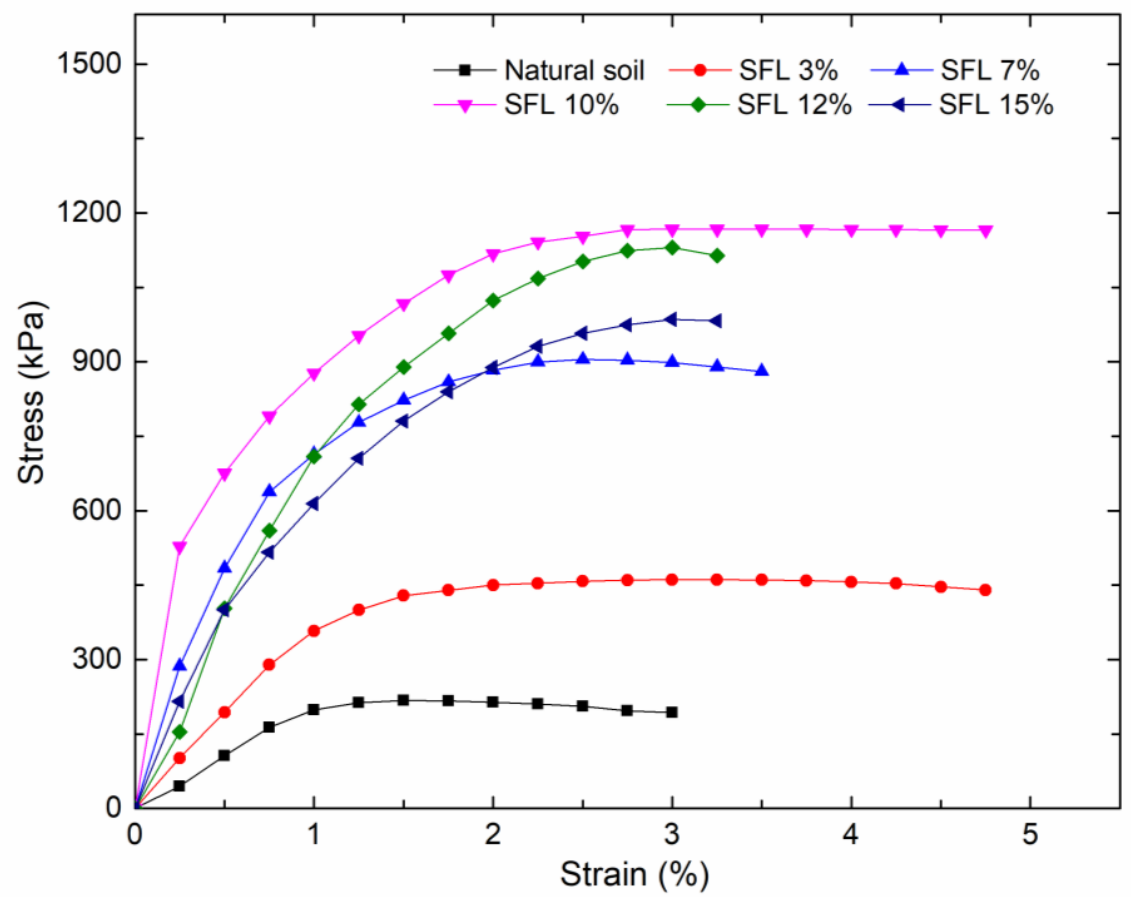

Fig. 8. Stress -strain curves of Sulfur-free lignin stabilized soil curing 60 days.

315 Fig.9 (a) shows the relationship between $\sigma_{c}$ and SFL content. It can be

316 observed that the maximum UCS is found at $10 \%$ SFL content, reaching $3171165 \mathrm{kPa}$ after 60 -days curing time. This value is approximately $600 \%$ 318 compared to the natural soil (about $214 \mathrm{kPa}$ ). This means SFL is extremely 

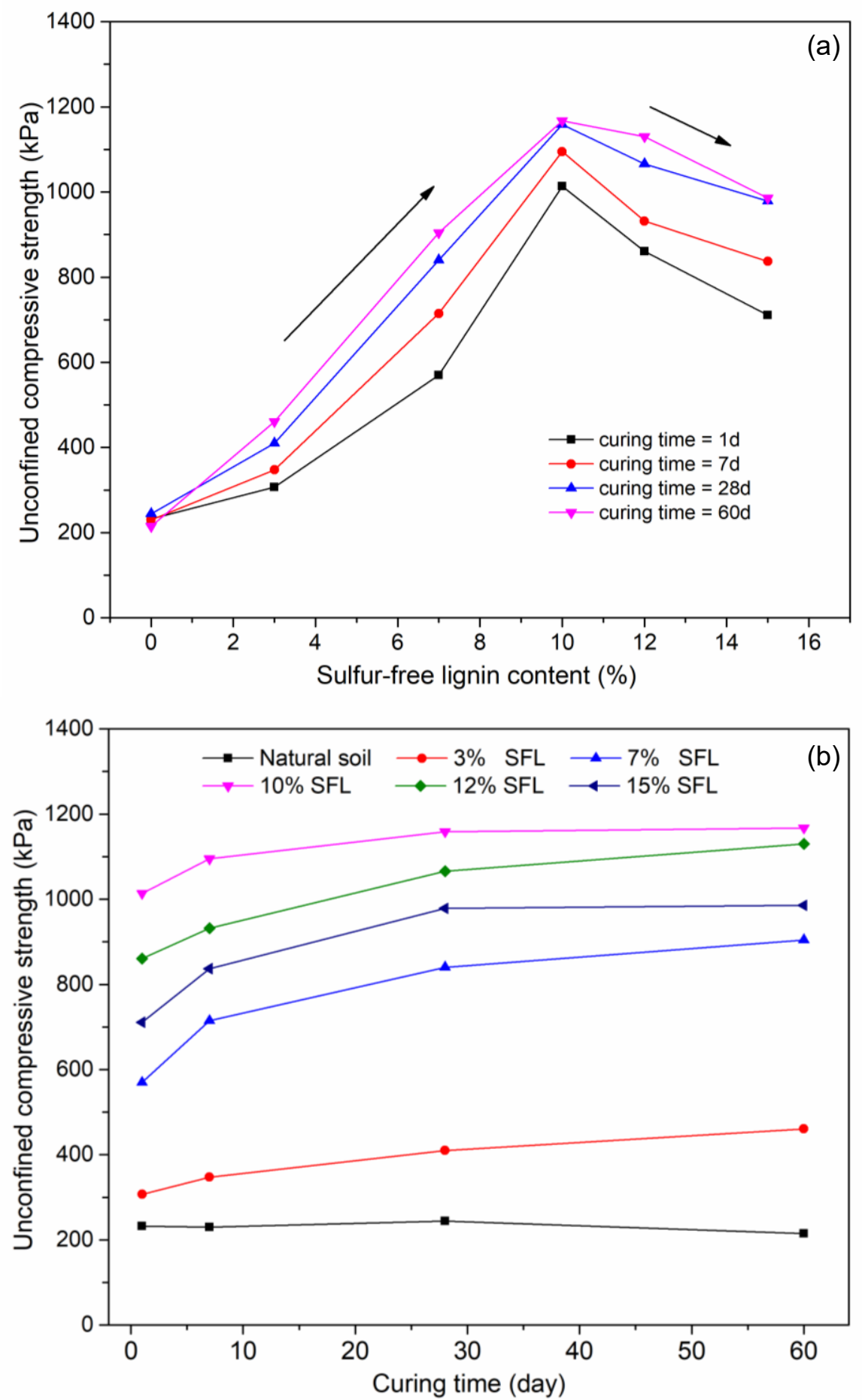

Fig. 9. Unconfined compressive strength for samples in terms of (a) different sulfur-free lignin content and (b) curing time.

320 efficient in improving strength. Fig. 9 (b) shows the variation in $\sigma_{c}$ with

321 different curing times. The strength increases with curing time, but the 322 trend slows down after 28 days. In addition, it is also worth to note that the 
323 stabilized soil has a distinct strength improvement when SFL content 324 exceeds $7 \%$.

325 The deformation modulus $\mathrm{E}_{50}$ as a function of $\sigma_{\mathrm{c}}$ is shown in Fig.10. 326 The relationship between $\mathrm{E}_{50}$ and $\sigma_{\mathrm{c}}$ is generally proportional 327 (UCS $\left.=9.07 \mathrm{E}_{50}, \mathrm{R}^{2}=0.959\right)$. As the deformation modulus $\mathrm{E}_{50}$ of the SFL 328 stabilized soil increases, so does $\sigma_{\mathrm{c}}$. In other words, both strength and 329 stiffness increase when adding SFL.

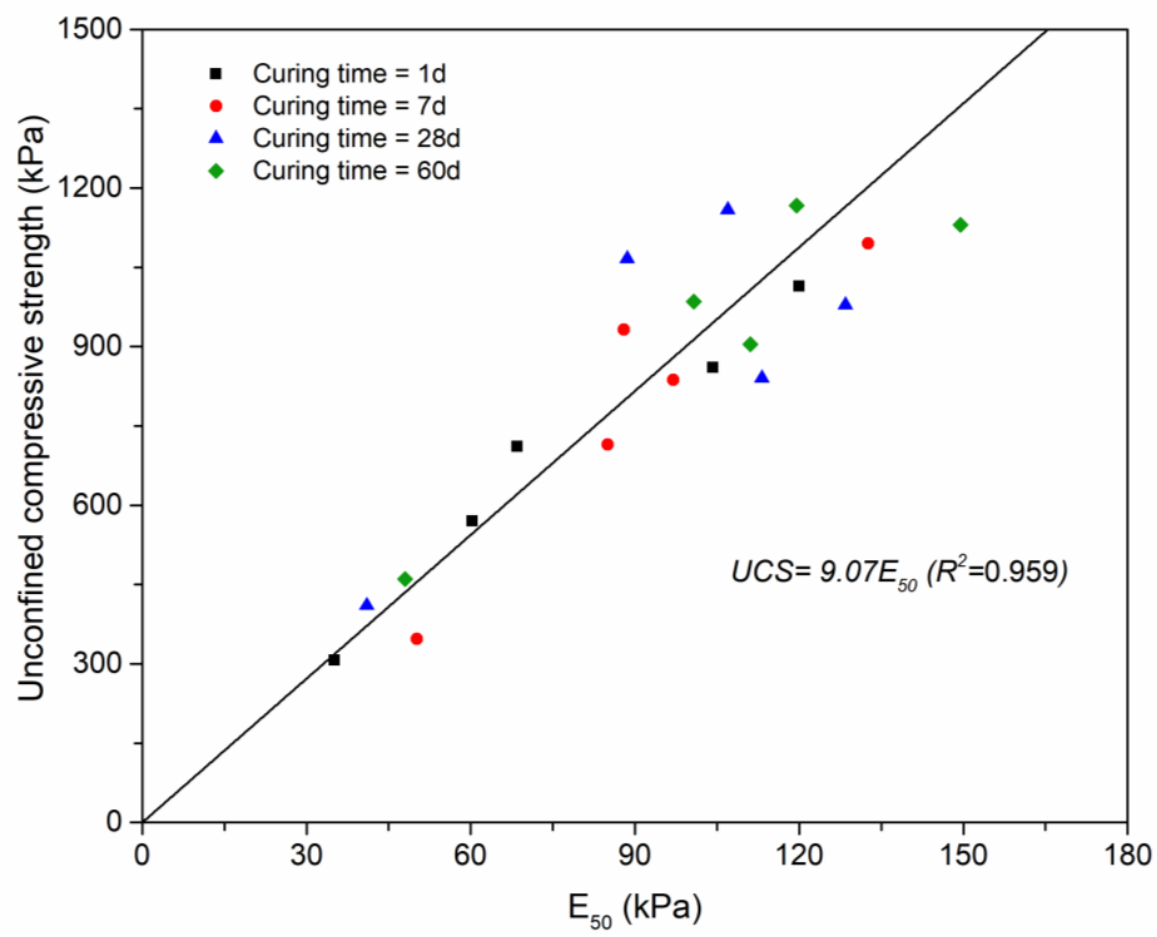

Fig. 10. Relationship between deformation modulus $E_{50}$ and unconfined compressive strength.

3313.4 X-Ray Diffraction (XRD) and Fourier Transform Infrared

332 Spectroscopy (FTIR) analysis

333 The powder diffraction patterns obtained from the XRD testing of the

334 natural soil, 10\% and 15\% SFL-stabilized soil are presented in Fig.11. 


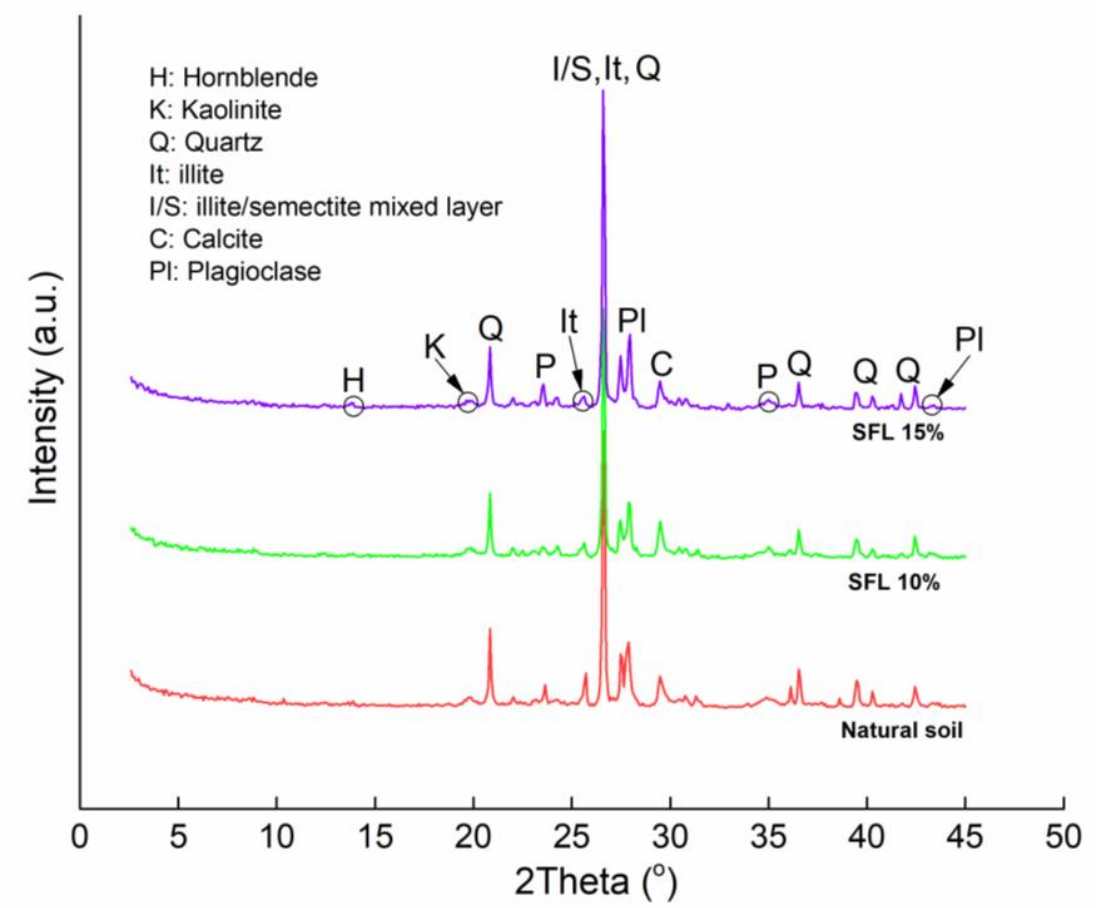

Fig. 11. XRD diffraction spectra of the natural soil, $10 \%$ and $15 \%$ SFL stabilized soil after 28-days curing.

336 Comparing the diffraction peak pattern of the natural soil with those of

337 SFL-stabilized soil, there is no obvious difference between them. This

338 means there are no new compounds generated that affect the soil

339 mineralogy. However, it also can be seen that some peak intensities (such

340 as $26^{\circ}, 35^{\circ}$ and $36.6^{\circ}$ ) become "weaker" or even disappear. This

341 phenomenon may be principally attributed to the amorphous properties of

342 lignin which restrict the diffraction of mineral atomic planes. In Fig. 11 the

343 main minerals are identified in the diffraction patterns of all samples

344 according to the Chinese standard (China, 2010a). For example, the

345 dominant peak intensity found at $26.6^{\circ}$ is caused by the overlap diffraction

346 of Quartz, Illite and Illite/Smectite mixed layer; The diffraction peaks of

347 Quartz are identified at $20.84^{\circ}, 36.52^{\circ}$ and 39.56 to $40.28^{\circ}$ In addition, the 
348 crystalline structure of Potassium and Calcite are found at around $19.76^{\circ}$ 349 and $25.48^{\circ}$. Therefore, the SFL does not generate new minerals through 350 chemical reaction to stabilize soil unlike lime or OPC.

351 The FTIR spectra for the natural and SFL stabilized soil in the middle352 infrared region $\left(4000-475 \mathrm{~cm}^{-1}\right)$ are presented in Fig.12. In general, the 353 spectra of the three samples are very similar, which indicates that SFL does 354 not cause huge changes in the functional groups of the soil structural 355 components. The broad band centered around $3416 \mathrm{~cm}^{-1}$ corresponds to the $356 \mathrm{OH}$ stretching vibration of inner-surface hydroxyl groups (Madejova and 357 Komadel, 2001). The presence of IR absorption peaks at $2520 \mathrm{~cm}^{-1}$ is 358 attributed to the $\mathrm{C}=\mathrm{O}$ stretch vibration and this band indicates that calcite 359 is present in the samples. The sharp peaks at around 1617 and $1460 \mathrm{~cm}^{-1}$ 360 may be related to aromatic $\mathrm{C}=\mathrm{C}$ stretching and aliphatic $\mathrm{C}-\mathrm{H}$, respectively 361 (Madari et al., 2006). Furthermore, the absorption band at $1027 \mathrm{~cm}^{-1}$ is 362 widely accepted to be due to the Si-OH of alumino-silicate lattice 363 associated with clay minerals (illite/smectite) (Tinti et al., 2015). This is 364 also consistent with the XRD results. At lower frequency, the peaks at 365 around 778 and $693 \mathrm{~cm}^{-1}$ could be ascribed to the Si-O symmetrical 366 bending vibrations which identifies the presence of Quartz, while the band 367 at around $513 \mathrm{~cm}^{-1}$ results from Si-O-Al bending (Eisazadeh et al., 2012; 368 Latifi et al., 2017).

369 However, there still are few noticeable changes in Fig. 12, for instance, 
370 the absorption band intensities show an increasing trend with SFL content 371 at around 2928 and 2851, 1512 as well as $1125 \mathrm{~cm}^{-1}$. Combined with the 372 already described FTIR spectra of SFL, these changes contribute to the 373 function group from sulfur-free lignin including aliphatic methylene 374 groups, deformation of aromatic ring and dialkyl ether linkages (Smidt et 375 al., 2002; Grube et al., 2006; Lisperguer et al., 2009).

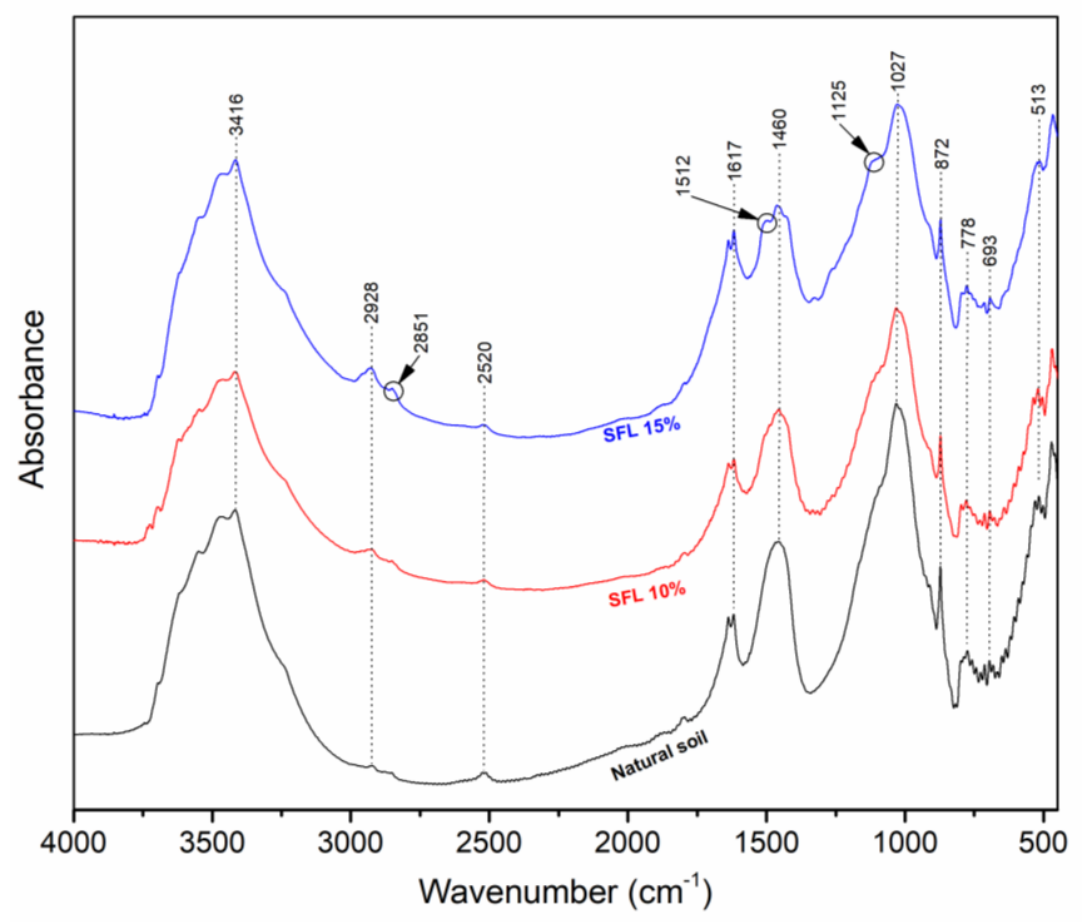

Fig. 12. FTIR spectra of the natural soil and 10\%, 15\% SFL stabilized soil after 28-day curing.

$377 \quad 3.5$ Micropore structure analysis

Fig. 13 (a) shows the variations of pore size distribution for the

379 natural soil and 10\% SFL-stabilized soil after 28-days curing, including 380 cumulative pore volume and differential pore radius distribution. 381 Compared to the natural soil, the total mercury intrusion of the stabilized 382 soil reduces around $0.13 \mathrm{ml} / \mathrm{g}$, from 0.162 to $0.148 \mathrm{ml} / \mathrm{g}$. Moreover, the 
383 amount of macropores (4 - $40 \mu \mathrm{m})$ obviously decreases corresponding to 384 an increase of the mesopores $(0.4-4 \mu \mathrm{m})$, as a result of SFL macropores 385 into filling macropores to reduce the pore space. At the same time, 386 according to the differential distribution curve, a typical bimodal and 387 unimodal pore size distributions can be seen for the natural soil and the $10 \%$ 388 SFL-stabilized soil respectively. The natural soil has a double porosity 389 fabric that contains two pores population which distribute around $0.02-$ $390 \quad 0.04 \mu \mathrm{m}$ diameter and $5-7 \mu \mathrm{m}$ diameter, respectively. However, for the 391 stabilized soil, the two population pores as observed in the natural soil 392 specimens are no longer apparent and most of them are transformed to 393 mesopores with diameter between 1 and $3 \mu \mathrm{m}$.

394 Fig. 13(b) illustrates the variations in pore size distribution for the $10 \%$ 395 SFL-stabilized soil with different curing times. The curve of total mercury 396 intrusion volume is similar for the 7-days and 28-days curing time (i.e. 0.05 $397 \mathrm{ml} / \mathrm{g}$ difference). With respect to the differential pore distribution, both the 398 7-days and 28-days curing specimens show a unimodal distribution with 399 noticeable differences in the mesopore scale. The families of mesopores 400 shift slightly towards the left from $4 \mu \mathrm{m}$ to $2 \mu \mathrm{m}$ as the curing time increases 401 from 7 to 28 days, indicating a reduction in the mean size of the mesopores 402 as the curing time increases. 

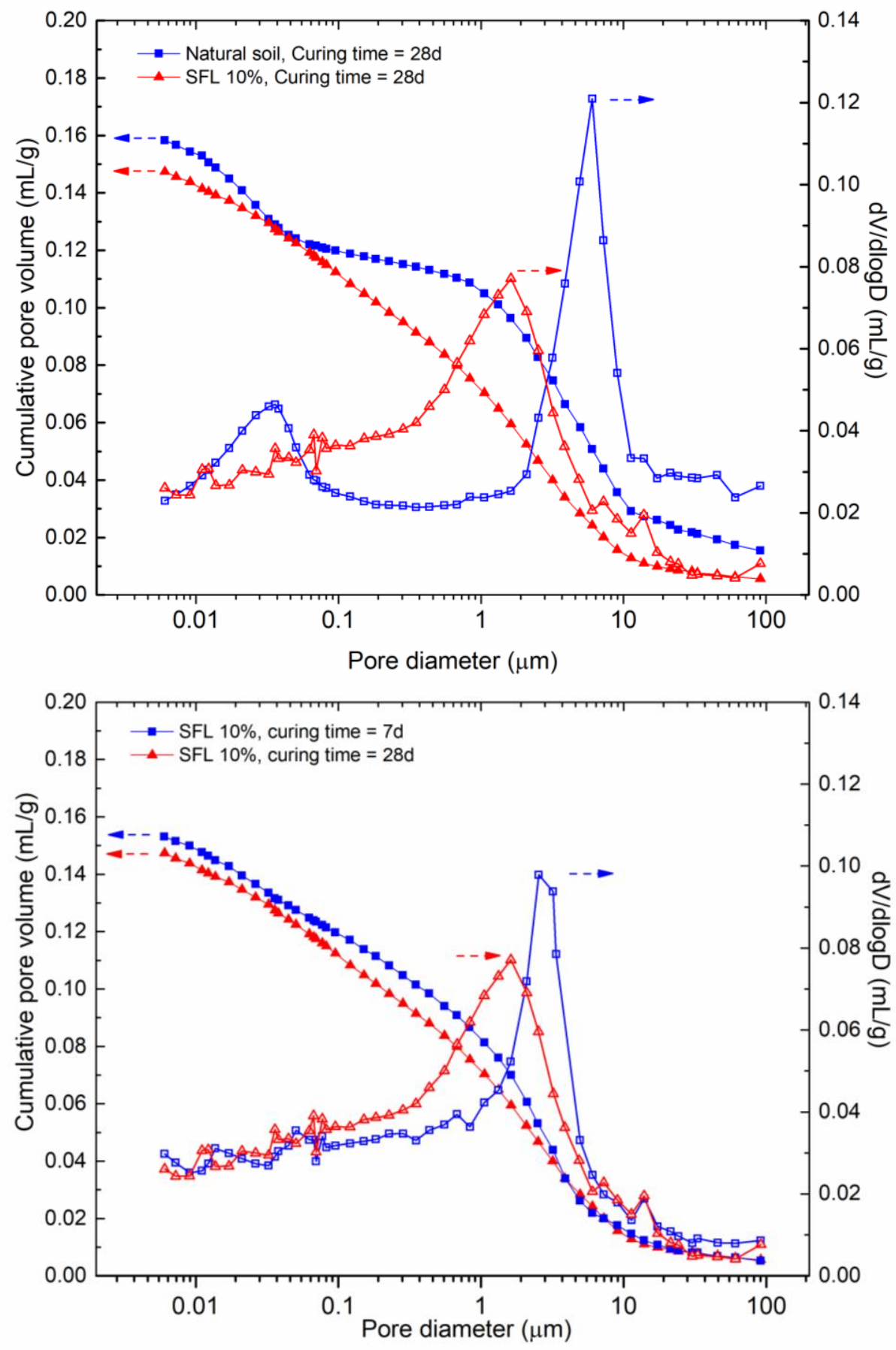

Fig. 13. (a) Mercury intrusion porosimetry results for the natural soil and $10 \%$ SFLstabilized soil after 28-days curing; (b) Mercury intrusion porosimetry results for the $10 \%$ SFL-stabilized soil after 7-days and 28-days curing.

405 3.6 Scanning electron microscopic (SEM) analysis

406 The photomicrographs of the natural and SFL-stabilized soil at 407 different curing times are shown in Fig. 15, which contains a series of SEM 
408 images magnified by 800 and 1000 times. Fig. 15 (a) shows that the 409 particles of the natural soil are distinctly separated with clear boundaries

410 and the particles mainly connect with each other by point-point or point-

411 surface contacts. Furthermore, it can be seen that there are more voids in

412 the matrix of the natural soil, which results in a looser structure. Fig. 15 (b)

413 indicates that the separated soil particles are coated and bonded with

414 adhesive material like natural polymer when adding SFL. A few

415 filamentous cellulose fibres impurity can also be recognized in the SFL-

416 stabilized soil. From Fig. 15 (c) and (d), it can be observed more clearly

417 under 1000 times magnification that when the SFL content increases to

$41815 \%$, most intergranular voids are filled and the soil particles are more

419 tightly packed through adhesive material formed by SFL, which improves

420 the soil structure to be more stable.

421 These observations are consistent with the results of UCS and MIP

422 discussed above. In addition, based on the results of XRD and XRF, it can

423 be deduced that the SFL reinforces the soil by filling intergranular pores

424 and forming cementing materials that physically bonds soil particles

425 together. Tingle et al. (2007), Vinold et al. (2010) and Alazigha et al. (2018)

426 thought that cementing could arise from electrostatic attraction between

427 lignin and soil minerals. 


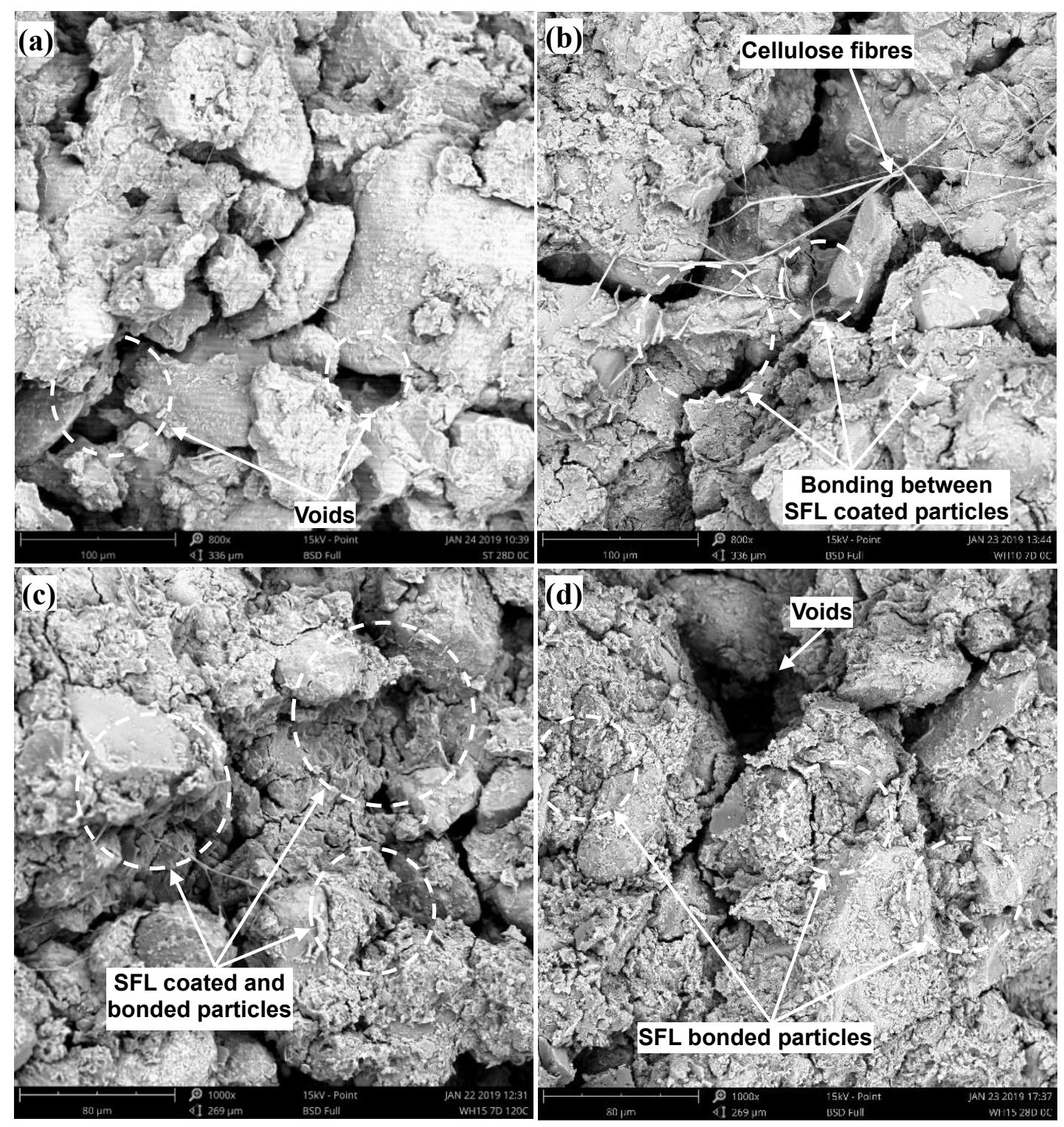

Fig. 15 Scanning electron microscopy images of the natural soil and the SFL-stabilized soil with different magnification: (a) natural soil (800x); (b) 10\% SFL stabilized soil after 7-day curing (800x); (c) 15\% SFL stabilized soil after 7-day curing (1000x); (d) 15\% SFL stabilized soil after 28-day curing (1000x).

430 This paper systematically investigates utilizing Sulfur-Free Lignin

431 (SFL) which is a sustainable, nontoxic and eco-friendly by-product from

432 bioethanol industry, to stabilize soil for geotechnical applications from the

433 viewpoint of engineering properties, micro-characteristic, mineral 
434 composition and function group. According to the present results, specific 435 conclusions can be drawn as follows:

436 1. The electrical resistivity of SFL-stabilized soil shows a reducing 437 trend with increasing SFL content. This is mainly because SFL 438 powders are mixed with an amount of soluble salts in the 439 pretreatment process for producing bioethanol, which increase 440 solute ion concentration in the pore fluid. However, the $\mathrm{pH}$ of 441 stabilized soil does not show significant changes, meaning SFL 442 would not lead to $\mathrm{pH}$ contamination risk usually caused by 443 traditional chemical stabilizer. In addition, different curing times do 444 not show obvious effects on the electrical resistivity.

445 2. The stress-strain curve of SFL-stabilized soil shows strain446 hardening behavior indicating better ductile properties. The 447 unconfined compressive strength $\left(\sigma_{\mathrm{c}}\right)$ of stabilized soils improved 448 significantly from $214 \mathrm{kPa}$ for the natural soil to $1165 \mathrm{kPa}$ for the $449 \quad 10 \%$ SFL-stabilized soil after 60 -days curing. This improvement is 450 approximately 6 times $\sigma_{\mathrm{c}}$ for the remoulded natural soil. Moreover, 451 the stabilized soil strength increased mainly in the first 28-day 452 curing. The $E_{50}$ and $\sigma_{\mathrm{c}}$ of SFL-stabilized soil show a proportional 453 relationship with a fitting equation of $\sigma_{\mathrm{c}}=9.07 \mathrm{E}_{50}\left(\mathrm{R}^{2}=0.959\right)$.

454 3. The results of Atterberg limits test illustrate that the liquid limit $\left(w_{L}\right)$ 455 and plastic limit $\left(w_{P}\right)$ of the stabilized soil increase with SFL, but 
the $w_{L}$ shows a more significant growth, which leads to $I_{P}$ increasing by $24 \%$ when adding $15 \%$ SFL. As a consequence, the stabilized soils change from medium plastic $\left(7<I_{P}<17\right)$ to highly plastic $\left(I_{P}>17\right)$. Just like the results of electrical resistivity, the curing time does not show any apparent influence on $I_{P}$.

4. The XRD patterns of the SFL-stabilized soil are similar with that of the natural soil over curing time, indicating that there is no new mineral generated after adding SFL. Furthermore, compared with the natural soil, some specific IR absorption peaks of SFL (2928, 2851, 1512 and $1125 \mathrm{~cm}^{-1}$ ) were also overserved in the FTIR spectrum for SFL-stabilized soil. But all these characteristic bands (functional group) are inherent of the materials rather than formed by chemical reaction.

469 5. The pore size distribution of the stabilized soil has an obvious change in that the small pores $(<0.04 \mu \mathrm{m})$ and macropores $(>5 \mu \mathrm{m})$ are gradually diminishing, resulting in a lower cumulative pore volume, as a result the porosity fabric changes from bimodal to unimodal. Through the different magnified SEM images, it can be clearly observed that the SFL coats and bonds isolated soil particles and fills the intergranular pores after 28-days curing which leads to a more stable fabric structure. These observations also explain well the test results of Atterberg limits, UCS and MIP. 
6. Based on the data obtained from XRD and FTIR tests, no apparent chemical change in mineralogy and function group are observed, but the formation of physical bonds between soil particles are visualized in SEM images. It may be concluded that the mechanism of SFL mixtures are more by physical rather than chemical means.

\section{Acknowledgements}

484 The authors are grateful for the financial support of the study presented 485 in this paper from the Key Program of International (Regional) 486 Cooperation and Exchange of National Natural Science Foundation (Grant 487 No. 41820104001), State Key Program of the National Natural Science 488 Foundation of China (Grant No. 41430642) and the Special Fund for Major 489 Scientific Instruments of the National Natural Science Foundation of China 490 (Grant No. 41627801). The authors also would like to appreciate Shaotao $491 \mathrm{Xu}$, Jiejie Shen, Feifan Gu, Yating Chen, and Mengxia Han from College 492 of Engineering Construction, Jilin University for their assistance in the 493 experimental process. In addition, the first author Yaowu Liu would also

494 like to thank the support from State Scholarship Fund of China Scholarship 495 Council (CSC NO. 201806170226).

\section{Reference}

497 Alazigha, D.P., Indraratna, B., Vinod, J.S., Heitor, A., 2018. Mechanisms 
498 of stabilization of expansive soil with lignosulfonate admixture.

499 Transportation Geotechnics 14, 81-92.

500 ASTM, 2002. ASTM D4219-02, 2002. Test Method for Unconfined

501 Compressive Sterength Index of Chemical-Grouted Soils.

502 ASTM, 2007. ASTM D4972-01, 2007. Standard Test Methods for $\mathrm{pH}$ of 503 Soils.

504 ASTM, 2010. ASTM D4318-10, 2010. Standard Test Methods for Liquid 505 Limit, Plastic Limit, and Plasticity Index of Soils.

506 Budhu, M., 2008. SOIL MECHANICS AND FOUNDATIONS, (With CD). 507 John Wiley \& Sons.

508 Cai, G., Zhang, T., Liu, S., Deng, Y., Zou, H., 2013. Relationship between

509 electrical resistivity and geotechnical characteristic parameters for Jiangsu 510 marine clay. Chinese Journal of Geotechnical Engineering 35, 1470-1477.

511 Chen, H., Wang, Q., 2006. The behaviour of organic matter in the process

512 of soft soil stabilization using cement. Bulletin of Engineering Geology

513 and the Environment 65, 445-448.

514 Chew, S., Kamruzzaman, A., Lee, F., 2004. Physicochemical and

515 engineering behavior of cement treated clays. Journal of geotechnical and

516 geoenvironmental engineering 130, 696-706.

517 China, N.E.A.o., 2010a. Analysis method for clay minerals and ordinary 518 non-clay minerals in sedimentary rocks by the X-ray diffraction, SY/T $519 \quad 5163-2010$. 
520 China, T.C.P.s.G.o.t.P.s.R.o., 2010b. Methods for chemical analysis of

521 silicate rocks. Standards Press of China.

522 Chio, C., Sain, M., Qin, W., 2019. Lignin utilization: A review of lignin

523 depolymerization from various aspects. Renewable and Sustainable 524 Energy Reviews 107, 232-249.

525 Delage, P., 1984. Influence De La Lyophilisation Sur La Structure D'une

526 Argile Sensible Du Quebec. Clay Minerals 19, 151-160.

527 Eisazadeh, A., Kassim, K.A., Nur, H., 2012. Solid-state NMR and FTIR 528 studies of lime stabilized montmorillonitic and lateritic clays. Applied Clay

529 Science 67-68, 5-10.

530 Farouk, A., Shahien, M.M., 2013. Ground improvement using soil-cement

531 columns: Experimental investigation. Alexandria Engineering Journal 52, $532 \quad 733-740$.

533 Grube, M., Lin, J.G., Lee, P.H., Kokorevicha, S., 2006. Evaluation of

534 sewage sludge-based compost by FT-IR spectroscopy. Geoderma 130, 324535333.

536 Indraratna, B., Muttuvel, T., Khabbaz, H., 2008. Investigating erosional 537 behaviour of chemically stabilised erodible soils, Geosustainablitiy and

538 Geohazard Mitigation, New Orleans, pp. 670-677.

539 Jafer, H., Atherton, W., Sadique, M., Ruddock, F., Loffill, E., 2018.

540 Stabilisation of soft soil using binary blending of high calcium fly ash and

541 palm oil fuel ash. Applied Clay Science 152, 323-332. 
542 Jiangying, L., Dimin, X., Xiong, L., Hills, C., Carey, P., Gardner, K., 2008.

543 Comparison of properties of traditional and accelerated carbonated

544 solidified/stabilized contaminated soils. Journal of Environmental

545 Sciences 20, 593-598.

546 Karim, M.R., Zain, M.F.M., Jamil, M., Lai, F.C., 2013. Fabrication of a

547 non-cement binder using slag, palm oil fuel ash and rice husk ash with

548 sodium hydroxide. Construction and Building Materials 49, 894-902.

549 Latifi, N., Eisazadeh, A., Marto, A., Meehan, C.L., 2017. Tropical residual

550 soil stabilization: A powder form material for increasing soil strength.

551 Construction and Building Materials 147, 827-836.

552 Lee, J.K., Shang, J.Q., 2014. Evolution of thermal and mechanical

553 properties of mine tailings and fly ash mixtures during curing period.

554 Canadian Geotechnical Journal 51, 570-582.

555 Lisperguer, J., Perez, P., Urizar, S., 2009. Structure and thermal properties

556 of lignins: characterization by infrared spectroscopy and differential

557 scanning calorimetry. Journal of the Chilean Chemical Society 54, 460-463.

558 Liu, Y., Chang, C.-W., Namdar, A., She, Y., Lin, C.-H., Yuan, X., Yang, Q.,

559 2019a. Stabilization of expansive soil using cementing material from rice

560 husk ash and calcium carbide residue. Construction and Building Materials

$561221,1-11$.

562 Liu, Y., Wang, Q., Liu, S., ShangGuan, Y., Fu, H., Ma, B., Chen, H., Yuan,

563 X., 2019b. Experimental investigation of the geotechnical properties and 
564 microstructure of lime-stabilized saline soils under freeze-thaw cycling.

565 Cold Regions Science and Technology 162, 32-42.

566 Madari, B.E., Reeves, J.B., Machado, P.L.O.A., Guimarães, C.M., Torres,

567 E., McCarty, G.W., 2006. Mid- and near-infrared spectroscopic assessment

568 of soil compositional parameters and structural indices in two Ferralsols.

569 Geoderma 136, 245-259.

570 Madejova, J., Komadel, P., 2001. Baseline studies of the clay minerals

571 society source clays: infrared methods. Clays and clay minerals 49,410 572432.

573 McCarter, W., 1984. The electrical resistivity characteristics of compacted

574 clays. Geotechnique 34, 263-267.

575 Modarres, A., Nosoudy, Y.M., 2015. Clay stabilization using coal waste 576 and lime - Technical and environmental impacts. Applied Clay Science 577 116-117, 281-288.

578 Nalbantoglu, Z., 2006. Lime stabilization of expansive clay, in: Amer Ali 579 Al-Rawas, M.F.A.G. (Ed.), Expansive soils: recent advances in 580 characterization and treatment. Taylor \& Franics/Balkema, pp. 341-348.

581 Önal, O., 2015. Lime stabilization of soils underlying a salt evaporation 582 pond: a laboratory study. Marine Georesources \& Geotechnology 33, 391 583402.

584 Pourhashem, G., Adler, P.R., Spatari, S., 2016. Time effects of climate 585 change mitigation strategies for second generation biofuels and co- 
586 products with temporary carbon storage. Journal of Cleaner Production 112, $587 \quad 2642-2653$.

588 Rahmat, M.N., Ismail, N., 2011. Sustainable stabilisation of the Lower 589 Oxford Clay by non-traditional binder. Applied Clay Science 52, 199-208. 590 Rocha, G.J.M., Gonçalves, A.R., Oliveira, B.R., Olivares, E.G., Rossell, 591 C.E.V., 2012. Steam explosion pretreatment reproduction and alkaline 592 delignification reactions performed on a pilot scale with sugarcane bagasse 593 for bioethanol production. Industrial Crops and Products 35, 274-279.

594 Samouëlian, A., Cousin, I., Tabbagh, A., Bruand, A., Richard, G., 2005.

595 Electrical resistivity survey in soil science: a review. Soil and Tillage 596 Research 83, 173-193.

597 Santoni, R.L., Tingle, J.S., Webster, S.L., 2002. Stabilization of silty sand 598 with nontraditional additives. Transportation research record 1787, 61-70.

599 Sharma, N.K., Swain, S.K., Sahoo, U.C., 2012. Stabilization of a clayey 600 soil with fly ash and lime: a micro level investigation. Geotechnical and 601 Geological Engineering 30, 1197-1205.

602 Smidt, E., Lechner, P., Schwanninger, M., Haberhauer, G., Gerzabek, M., 603 2002. Characterization of waste organic matter by FT-IR spectroscopy: 604 application in waste science. Applied Spectroscopy 56, 1170-1175.

605 Sreekrishnavilasam, A., Rahardja, S., Kmetz, R., Santagata, M., 2007. Soil 606 treatment using fresh and landfilled cement kiln dust. Construction and 607 Building Materials 21, 318-327. 
608 Surdahl, R.W., Woll, J.H., Marquez, H.R., 2007. Stabilization and dust 609 control at the Buenos Aires national wildlife refuge, Arizona.

610 Transportation Research Record 1989, 312-321.

611 Thives, L.P., Ghisi, E., 2017. Asphalt mixtures emission and energy

612 consumption: A review. Renewable and Sustainable Energy Reviews 72, $613 \quad 473-484$.

614 Tingle, J.S., Newman, J.K., Larson, S.L., Weiss, C.A., Rushing, J.F., 2007.

615 Stabilization mechanisms of nontraditional additives. Transportation 616 Research Record 1989, 59-67.

617 Tingle, J.S., Santoni, R.L., 2003. Stabilization of clay soils with 618 nontraditional additives. Transportation Research Record 1819, 72-84.

619 Tinti, A., Tugnoli, V., Bonora, S., Francioso, O., 2015. Recent applications 620 of vibrational mid-Infrared (IR) spectroscopy for studying soil components:

621 A review. Journal of Central European Agriculture 16, 0-0.

622 Vakili, A.H., Ghasemi, J., bin Selamat, M.R., Salimi, M., Farhadi, M.S.,

623 2018. Internal erosional behaviour of dispersive clay stabilized with 624 lignosulfonate and reinforced with polypropylene fiber. Construction and 625 Building Materials 193, 405-415.

626 Vinod, J., Mahamud, M.A., Indraratna, B., 2012. Elastic modules of soils 627 treated with lignosulfonate, 11th Australia- New Zealand Conference on

628 Geomechanics: Ground Engineering in a Changing World, pp. 487-492.

629 Vinod, J.S., Indraratna, B., Al Mahamud, M.A., 2010. Stabilisation of an 
630 erodible soil using a chemical admixture. Ground Improvement 163 (1),

$631 \quad 43-52$.

632 Wang, D., Du, Y., Xiao, J., 2019a. Shear properties of stabilized loess using

633 novel reactive magnesia-bearing binders. Journal of Materials in Civil

634 Engineering 31, 04019039.

635 Wang, D., Wang, H., Jiang, Y., 2019b. Water Immersion-Induced Strength

636 Performance of solidified soils with reactive $\mathrm{MgO}-\mathrm{A}$ green and low

637 carbon binder. Journal of Testing and Evaluation 47, 1569-1585.

638 Wang, Y., Cheng, M.-H., 2018. Greenhouse gas emissions embedded in

639 US-China fuel ethanol trade: A comparative well-to-wheel estimate.

640 Journal of Cleaner Production 183, 653-661.

641 Yano, S., Murakami, K., Sawayama, S., Imou, K., Yokoyama, S., 2009.

642 Ethanol production potential from oil palm empty fruit bunches in

643 Southeast Asian countries considering xylose utilization. Journal of the

644 Japan Institute of Energy 88, 923-926.

645 Zhang, T., Cai, G., Liu, S., 2017a. Application of lignin-based by-product

646 stabilized silty soil in highway subgrade: A field investigation. Journal of

647 Cleaner Production 142, 4243-4257.

648 Zhang, T., Cai, G., Liu, S., 2018a. Assessment of mechanical properties in

649 recycled lignin-stabilized silty soil as base fill material. Journal of Cleaner

650 Production 172, 1788-1799.

651 Zhang, T., Cai, G., Liu, S., 2018b. Reclaimed lignin-stabilized silty soil: 
652 undrained shear strength, Atterberg limits, and microstructure 653 characteristics. Journal of Materials in Civil Engineering 30, 04018277.

654 Zhang, T., Liu, S., Cai, G., Puppala, A.J., 2015. Experimental investigation

655 of thermal and mechanical properties of lignin treated silt. Engineering 656 Geology 196, 1-11.

657 Zhang, X., Shen, J., Wang, Y., Qi, Y., Liao, W., Shui, W., Li, L., Qi, H., Yu, 658 X., 2017b. An environmental sustainability assessment of China's cement 659 industry based on energy. Ecological Indicators 72, 452-458. 